\title{
Theoretical construct of strategic control systems
}

\author{
Zulnaidi Yaacob*
}

Universiti Sains Malaysia

\begin{tabular}{|c|c|}
\hline A R T I C L E I N F O & A B S T R A C T \\
\hline $\begin{array}{l}\text { Article history: } \\
\text { Received April 17, } 2012 \\
\text { Accepted } 11 \text { June } 2012 \\
\text { Available online } \\
\text { June } 122012 \\
\text { Keywords: } \\
\text { Strategic control systems } \\
\text { Quality management }\end{array}$ & $\begin{array}{l}\text { This paper presents the development of an instrument for measuring strategic control systems } \\
\text { (SCS). Although SCS has received considerable attention in the literature, most of the } \\
\text { discussions, on the elements that constitute SCS, are limited to descriptive statements. Thus, the } \\
\text { theoretical construct of SCS suffers from lack of extensive statistical validation procedures. } \\
\text { However, there are a few authors that had initiated the development of an instrument to } \\
\text { measure the SCS. Their small effort had also been criticized due to the inconsistency among } \\
\text { authors in defining SCS, which would likely affect the validity of the instrument being } \\
\text { developed. Given this lacuna, this paper has developed and validated an instrument for } \\
\text { conceptualizing SCS, specifically under the environment of Quality Management strategy. } \\
\text { Based on a careful and systematic process of instrument development, this paper revealed that } \\
\text { SCS consists of two important dimensions, namely strategy implementation and strategic } \\
\text { resource allocation. In developing this instrument, a total number of } 205 \text { respondents were } \\
\text { involved. The findings reported in this paper would benefit future researchers in measuring } \\
\text { SCS, particularly for survey-based research. }\end{array}$ \\
\hline
\end{tabular}

C 2012 Growing Science Ltd. All rights reserved.

\section{Introduction}

Quality Management (QM) is regarded as an effective means for businesses to survive in a turbulent market, due to its significant effects in improving customer satisfaction (Kumar, Garg, \& Garg, 2010). It is a long term strategy that focus on continuous improvement (Yu, To, \& Lee, 2012), and its implementation is never an easy process (Ali, Mahat, \& Zairi, 2007). Without proper planning and monitoring systems, many QM-organizations have been reported to fail in achieving their quality results (Haupt \& Whiteman, 2004). As a long term strategy, issues related to the implementation of QM are anticipated to be more complex and critical, compared to a shorter term strategy. Given that, long term strategy planning must be flexible enough to accommodate the future changes that may happen in the internal and external environments, where some of them are unplanned changes that happen without any indication or warning. Although the process of planning a strategy is a daunting task, the execution stage of a strategy is more difficult. The difficulty in strategy implementation is

\footnotetext{
* Corresponding author.

E-mail addresses: zulnaidi@usm.my (Z. Yaacob) 
reflected in a statement by Kaplan and Norton (2000), where according to them more than $70 \%$ of organizations around the world have failed to reap good results from their strategy.

Due to this unfavorable scenario, the issue of fit between strategy and strategic control systems (SCS) has been explored by many researchers (Akroyd \& Maguire, 2011; Takahiro \& Jia, 2012). They investigated the role of control systems in the planning and execution of a strategy. Not limited to the various models and theories proposed, the study on SCS had used different measures to conceptualize the construct of SCS. Most researchers used ad-hoc measures to study SCS. At present, there is no agreed definition of what actually constitutes SCS. Although a few scholars had offered a definition of SCS, many of them were reported many years ago. With the scenario that this world keeps changing rapidly, which is more so with the way organizations work. As a consequence, this may also reduce the validity of definitions offered ten or 20 years ago. To overcome this phenomenon, a definition of SCS under the contemporary environment should be developed. Without a continual effort to develop a new instrument with robust statistical tests, the development of control systems as a research area may weaken. Therefore, more scientific effort is needed to shed light on this phenomenon. In view of this under developed area, this study contributes to the control systems literature by developing an instrument to measure SCS. Therefore, the objectives presented in this paper are (1) to identify the dimensions of SCS construct as narrated in the literature, and (2) to develop valid and reliable scales for measuring SCS.

\subsection{Strategic control systems}

Although the literature on management control systems has been developed extensively, its fundamental issue related to a well-accepted definition of SCS is still unresolved. This section discusses the variations in the definitions of SCS as laid down by different authors. Although discrepancy between the definitions is expected, the similarities in their definitions are also detected. This scenario leads to the conclusion that more effort needs to be executed in order to provide another alternative definition of SCS. Offering other alternatives does not mean adding further doubt to the literature, but to enrich the literature in preparation for the long journey ahead in obtaining a wellaccepted definition of SCS. Among the authors that had offered definition of SCS were Schendel and Hofer (1979, p18). They narrated SCS as follows:

Strategic control focuses on the dual question of whether: (1) the strategy is being implemented as planned; and (2) the results produced by the strategy are those intended. The basic criteria used to answer these questions are derived from: (1) the strategy and action plans developed to implement strategy; and (2) the performance results that strategy is expected to produce. If a deviation occurs, the feedback takes place and the strategic management process recycles.

The definition of SCS as narrated by Schendel and Hofer above contains two critical points. Firstly, the management needs to develop a plan for implementing a strategy. Secondly, the progress of strategy needs to be monitored and measured and if significantly bad variance between achieved and targeted results exists, it must be communicated to the people who are responsible and capable for taking corrective action. From this definition, it can be anticipated that SCS consists of a cycle process, namely planning, monitoring, feedback, and back to planning again.

Other definitions of SCS were offered by Goold and Quinn (1990). Their definitions did not deviate far from the SCS definition by Schendel and Hofer. According to Goold and Quinn (1990), SCS refers to:

the process which allows senior management to determine whether a business unit is performing satisfactorily, and which provides motivation for business unit management to see that it continues to do so. It therefore normally involves the agreement of objectives for the business between different level of management, 
monitoring of performance against these objectives and feedback on result achieved, together with incentives and sanctions for business management.

By scrutinizing the definition of SCS offered by Schendel and Hofer (1979), and Goold and Quinn (1990), the criticism by Simons (1990) on SCS provides some fruit for thought. Simons (1990) criticized that the definitions of SCS lead to a perception of SCS as a process for ensuring that the implemented strategy is on track by having two distinct stages of planning and implementation. However, only strategy implementation is closely associated with control activities. In other words, SCS plays no or an invisible role in the planning stage.

Therefore, Simons suggested three types of formal control systems which can be utilized by managers for executing their organizational strategy successfully. Simons described these three types of control systems, namely as

a) diagnostic control systems, which refers to periodical and systematic control systems aimed to measure progress against plans, and it concentrates on planned strategies;

b) interactive control systems, which refers to systems with regular discussions within the organization, and it focuses on the designing of strategies; and

c) boundary control systems, which refers to systems aimed to communicate the border of permissible actions to all employees.

A review paper on strategic control by Goold and Quinn (1990) revealed that strategic management literature had advocated the establishment of SCS for monitoring the implementation of a strategy. According to Ittner and Larcker (1997), SCS refers to control systems, in any form that focused on the successful implementation of strategic activities. In other words, SCS can be termed as strategy focused control systems. In this study, the SCS was investigated under the environment of QM strategy. Therefore, the SCS conceptualized in this study refers to QM-focused control systems.

\section{Construct development}

Acknowledging the fact that the SCS construct has been defined in numerous and inconsistent ways in previous studies, this study decided to use a strategy where one model was selected as grounds for developing a framework of SCS. The selected model then is supported by other researchers. For this purpose, the framework of Kaplan and Norton (1996) was selected as representing the core of SCS construct due to the fact that the model has been well recognized in the literature. Given that, the variable of SCS was conceptualized using the four dimensions of strategic control framework, as suggested by Kaplan and Norton (1996).

The four dimensions refer to: (1) clarifying and translating the vision; (2) communicating and linking; (3) planning and target setting; and (4) strategic feedback and learning. The degree to which an organization practices SCS is measured using eleven items. The items were anchored on a five point Likert scale: (1) strongly disagree, (2) somewhat disagree, (3) neither agree nor disagree, (4) somewhat agree, (5) strongly agree. The average score of the responses to those items was calculated. The higher score reflects the higher elements of SCS existing in the organizations under study.

The first dimension of SCS clarifies and translates the strategy. QM strategy requires involvement from the top management, middle managers, and operational workers to yield continuous improvement (Powell, 1995). To integrate these groups, it requires a system that can be utilized to foster the common shared goal among them. This function can be played well by SCS, particularly in aligning the mindset, activities, and decisions taken by different parties within an organization. As a result, the probability of attaining QM objectives would be higher. However, consensus among organizational members can only be obtained if the organizational strategy had been clarified first. By having SCS, it helps organizations to translate the philosophy of QM strategy into operational measures (Hoque, 2003). This would result employees to view conceptual ideas as a clearer picture. 
In order to translate the QM strategy into operational terms, deployment of SCS to each operational unit might be a wise step.

\section{Table 1}

Dimensions of SCS

\begin{tabular}{|c|c|c|}
\hline Four dimensions of SCS & $\begin{array}{l}\text { Sub dimensions [code in data } \\
\text { analysis] }\end{array}$ & The dimension is supported by \\
\hline \multirow[t]{3}{*}{$\begin{array}{l}\text { Clarifying and translating the } \\
\text { strategy }\end{array}$} & $\begin{array}{l}\text { Translating the strategy into action } \\
\text { that is understood [scs1] }\end{array}$ & $\begin{array}{l}\text { Schendel \& Hofer (1979); Ittner \& Larcker } \\
\text { (1997); Sinclair \& Zairi (2001) }\end{array}$ \\
\hline & $\begin{array}{l}\text { Strategy is translated into action that } \\
\text { can be communicated }[\operatorname{scs} 2]\end{array}$ & $\begin{array}{l}\text { Schendel \& Hofer (1979); Ittner \& Larcker } \\
\text { (1997); Sinclair \& Zairi (2001) }\end{array}$ \\
\hline & $\begin{array}{l}\text { Gaining consensus among employee } \\
\text { on strategy [scs } 3 \text { ] }\end{array}$ & $\begin{array}{l}\text { Goold \& Quinn (1990); Ittner \& Larcker } \\
\text { (1997) }\end{array}$ \\
\hline \multirow[t]{3}{*}{ Communicating and linking } & Linking rewards to strategy $[\operatorname{scs} 4]$ & $\begin{array}{l}\text { Goold \& Quinn (1990); Goold \& Quinn } \\
\text { (1993); Ittner \& Larcker (1997); Sinclair \& } \\
\text { Zairi (2001) }\end{array}$ \\
\hline & $\begin{array}{l}\text { Strategy is communicated to entire } \\
\text { organization }[\operatorname{scs} 5]\end{array}$ & $\begin{array}{l}\text { Goold \& Quinn (1990); Ittner \& Larcker } \\
\text { (1997) }\end{array}$ \\
\hline & $\begin{array}{l}\text { Strategy is translated into specific } \\
\text { measures at operational level [scs6] }\end{array}$ & $\begin{array}{l}\text { Schendel \& Hofer (1979); Goold \& Quinn } \\
\text { (1990); Ittner \& Larcker (1997) }\end{array}$ \\
\hline \multirow[t]{3}{*}{ Planning and target setting } & $\begin{array}{l}\text { Resource allocation are based on } \\
\text { quality initiatives [scs7] }\end{array}$ & Goold \& Quinn (1990) \\
\hline & $\begin{array}{l}\text { Having long term plan for quality } \\
\text { initiatives [scs } 8 \text { ] }\end{array}$ & $\begin{array}{l}\text { Schendel \& Hofer (1979); Goold \& Quinn } \\
\text { (1990); Goold \& Quinn (1993); Ittner \& } \\
\text { Larcker (1997); Sinclair \& Zairi (2001) }\end{array}$ \\
\hline & $\begin{array}{l}\text { Programs that are not contributing to } \\
\text { quality initiatives are eliminated } \\
\text { [scs9] }\end{array}$ & Kaplan \& Norton (1996) \\
\hline \multirow[t]{2}{*}{ Strategic feedback and learning } & $\begin{array}{l}\text { Management review reports on } \\
\text { quality plan/result/problem }[\operatorname{scs} 10]\end{array}$ & $\begin{array}{l}\text { Schendel \& Hofer (1979); Goold \& Quinn } \\
\text { (1990); Goold \& Quinn (1993); Ittner \& } \\
\text { Larcker (1997) }\end{array}$ \\
\hline & $\begin{array}{l}\text { Management gives feedback on } \\
\text { quality program/results [scs } 11]\end{array}$ & $\begin{array}{l}\text { Schendel \& Hofer (1979); Goold \& Quinn } \\
\text { (1990); Goold \& Quinn (1993); Ittner \& } \\
\text { Larcker (1997) }\end{array}$ \\
\hline
\end{tabular}

The second element of SCS is communicating the strategy throughout the organization and linking the strategy with reward systems. To execute QM successfully, it requires an organization-wide effort. There is no other choice but to constantly communicate the QM strategy to all members within the organization because QM is the responsibility of each and every organizational member. In doing so, QM strategy needs to be articulated to all members to strengthen their understanding and increase their commitment towards QM strategy. SCS would be able to link results with reward and punishment systems (Goold \& Quinn, 1990). It requires the recognition, promotion, and compensation activities being able to motivate employees in enhancing their contribution in achieving strategic objectives. Having said this, employees can understand what is expected from them in order for them to be rewarded. Therefore, a reward system under SCS must be geared to achieving strategic objectives (Kaplan \& Norton, 1996).

The third element of SCS is planning and target setting. SCS unifies QM planning and operational budgeting through the budgeting of adequate resource for QM activities. Effective implementation of SCS includes the development stage of action plans and objectives for achieving the strategic objectives (Ittner \& Larcker, 1997). Selection of strategic objectives involves activities such as measures of strategic progress, determine and review objectives, milestones, action, and result (Goold \& Quinn 1993). To be comprehensive, the strategic objectives include both financial and nonfinancial measures of performance, which are based on the long-term perspective.

Having the planning and target setting management process, SCS enables organizations to: (1) quantify the targeted long-term performance, (2) identify mechanism and resource, (3) and establish 
short-term targets for both financial and non-financial performances (Kaplan \& Norton, 1996). SCS also helps an organization to integrate its strategic planning with its annual budgeting process (Kaplan \& Norton, 1996). This function is critical since the manager's action in executing the strategic plan must be consistent with established strategic objectives. They need to avoid heavy emphasis on short-term financial results as restricted in the budget (Goold \& Quinn, 1990; Govindarajan \& Gupta, 1985). As asserted by Goold and Quinn (1993), the link between objectives of budget and strategic objectives must be aligned since inconsistency between them may cause ambiguity among managers. This alignment is important for motivating managers to consistently put high commitment on strategic initiatives. Focusing too much on short-term financial performance is likely to devastate the organizational strategic objectives. It is therefore desirable that the budget system is linked to the long-term strategy in order to execute the strategy successfully. Therefore, financial and physical resources, long term budget, and annual cash flow must be aligned with the long-term strategy.

The fourth element of SCS is strategic feedback and learning. Today's organizations operate in a dynamic environment where changes are occurring every minute. To accommodate this situation, managers need to receive feedback about the implementation of long-term strategies frequently (Kaplan \& Norton, 1996). This would enable them to perform internal and external monitoring on performance against strategic objectives (Ittner \& Larcker, 1997). Having periodic and systematic internal and external reviews also provide feedback on actual results versus planned outcome. Therefore, it would allow managers to reconsider actions or strategies when the result falls below an established acceptable line or point.

The internal monitoring process enables managers and employees to be in accordance with the strategic plan (Kaplan \& Norton, 1996). This process may involve regular reports on progress against intended objectives (Goold \& Quinn, 1993). The reports may cover the issues on validity of the critical assumptions behind the strategies, the progress of key activities are on schedule, or validity of long-term targets. The frequent report on strategic results versus expectations permits timely corrective action to be taken, far before overall performance is badly affected (Ittner \& Larcker, 1997). Any indicators of failure to meet strategic objectives should be regarded as indicators for intervention action (Goold \& Quinn, 1993).

The SCS also monitors the external environment. Monitoring external environment provides feedback on the strategy success in the environment based on marketplace, customer, and competitor responses. External monitoring also provides the management with the input related to external threats to the strategic plan (Schreyogg \& Steinman, 1987; Bromwich, 1990). External monitoring may involve managing customer and supplier relationships and benchmarking activities (Sinclair \& Zairi, 2001). In addition to assessment of strategic progress relative to predetermined goals or competitors, external monitoring enables the organizations to validate whether the predetermined strategic plan is still valid under the new changing environment (Schreyogg \& Steinman, 1987).

\section{Methodology}

The measurement instrument in this study was developed systematically. The stages involved in developing the instrument for this study are as follows:

1. An extensive literature review was done covering descriptive articles as well as empirical papers. Literature review is an important source to support the content validity of a developed questionnaire.

2. Interviews with experts were arranged to evaluate the content and presentation of questionnaire.

3. A pilot study involving 32 respondents was performed to check the quality of questionnaire in terms of design, language, and arrangement. The reliability and validity 
analyses were also performed before revision on the questionnaire was made. A few changes were made based on the recommendations received from the respondents.

4. The main study was carried out involving 205 employees of the public service as respondents. They were selected using the stratified random sampling method. The approach aims to provide adequate representative from each identified strata.

5. Statistical analysis was run to test the reliability and validity of the instrument. Exploratory and confirmatory analysis was also performed.

Respondents of this study were officers from local governments in Malaysia. They were selected using stratified random sampling. Each local government with six to eight departments each was considered a stratum. The random sampling was done at strata level, so all departments attached to a selected stratum was considered as the unit of analysis. Out of 250 questionnaires distributed, only 205 replied and used for further analysis. The questionnaire was designed and printed in a professional looking booklet form. In addition, a cover letter was attached to the questionnaire to explain the purpose of study as well as to guarantee respondents about the confidentiality of their responses. A prepaid postal envelope was also provided to the respondent and a series of follow-up calls were also done to assist in increasing the response rate.

\section{Reliability and Validity Test}

Cronbach's alpha coefficient was used to evaluate the reliability of the instrument. The threshold suggested by Nunnaly (1978) was benchmarked to evaluate the developed questionnaire. The result of reliability test of the 11 items was 0.920 , thus suggesting a good level of reliability. Although reliability is a prerequisite of good measurement, it is inadequate to conclude the goodness of a measurement (Churchill, 1979). One measurement with high reliability is likely an invalid measurement as it does not measure the intended construct. In other words, validity refers to the extent a measurement measures what it is intended to measure (Nunnaly, 1978). Statistical literature discusses three types of validity: content validity, criterion related validity, and construct validity.

A construct is said to have content validity if the construct is represented by items that cover all important aspects of the construct, and it is consistent with the discussion in the literature. In order to achieve content validity, exhaustive literature was reviewed. In addition, thorough discussions with three academicians and eight practitioners were performed to construct the questionnaire. Given that, the questionnaire items of this study were generally considered to have good content validity. For criterion related validity, Kerlinger and Lee (2000) asserted that this type of validity is difficult to test. The third category of validity is construct validity, which can be tested using factor analysis. This analysis allows us to examine whether items are tapping into their intended construct.

\section{Exploratory Factor Analysis}

Table 2

KMO and Bartlett's test

\begin{tabular}{ll}
\hline Kaiser-Meyer-Olkin Measure of Sampling Adequacy & 0.825 \\
\hline Barlett's test of sphericity & \\
Approximate Chi-square & 247.881 \\
Df & 55 \\
Sig & 0.00 \\
\hline
\end{tabular}

The Barlett's test of sphericity is significant and the Kaiser-Meyer-Olkin (KMO) measures of sampling adequacy is greater than 0.6. Therefore the application of factor analysis on this data was considered appropriate. In addition, the value of measures of sampling adequacy (MSA) as indicated in Table 2 is above the acceptable level of 0.5 . Thus, it provides evidence of the factorability of items. 
Table 3

Principal component analysis

\begin{tabular}{lllllll}
\hline Factor & \multicolumn{2}{l}{ Factor loadings } & & Eigen-value & \% of variance & Cumulative \% \\
\hline 1 & $0.695(1) ;$ & $0.553(2) ;$ & $0.918(3) ;$ & 6.319 & 57.443 & 57.443 \\
& $0.759(4) ;$ & $0.752(9) ;$ & $1.02(10) ;$ & & & \\
& $0.624(11)$ & & & & & \\
2 & $0.595(5) ;$ & $0.936(6) ;$ & $0.865(7) ; 1.464$ & 13.308 & 70.751 \\
& $0.668(8)$ & & & & & \\
\hline
\end{tabular}

Note: Numbers in parentheses refer to number of items.

Table 3 shows the result of the factor analysis of 11 items, using the varimax rotation. The result produced two factors which have eigen-values greater than one and the percentage of variance that can be explained by the two factors is $70.75 \%$. The following scree plot also suggests that there are two factors.

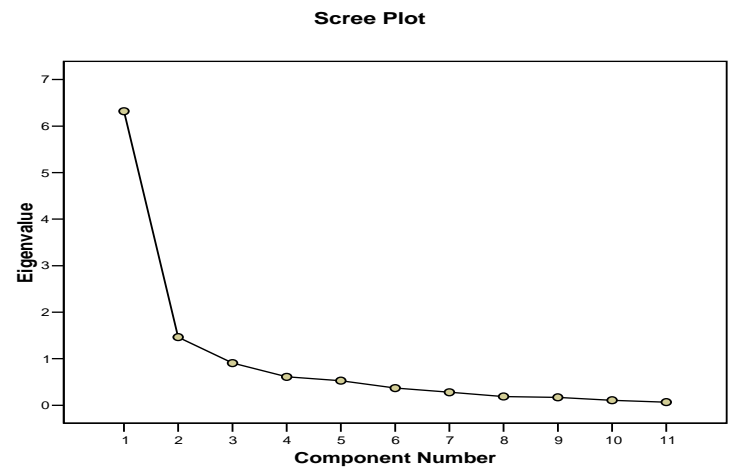

Fig. 1. Scree plot of construct

After grouping the items into two related factors, the reliability of the construct was re-examined. The results of reliability test are presented in Table 4. The Cronbach's coefficient alpha ( $\alpha$ ) for Strategy Implementation (Factor 1) was 0.906, thus suggesting a good level of reliability, while for Strategic Resource Allocation (Factor 2) was 0.865 , also suggesting a good level of reliability.

\section{Table 4}

Reliability test

\begin{tabular}{lll}
\hline Factor & Number of Items & Cronbach's Alpha \\
\hline Factor 1 (strategy implementation) & 7 & 0.906 \\
Factor 2 (strategic resource allocation) & 4 & 0.865 \\
\hline
\end{tabular}

\subsection{Confirmatory factor analysis}

The measurement models were further assessed using confirmatory factor analysis. The measurement models specify the relationship between observed measures and their latent variable. There are a number of indices that can be used as a benchmark in evaluating the model fit. Although the chi square statistics is the most popular index, it is very sensitive to the sample size. Given that, other indices should also be examined in determining model fit (Bollen, 1989). Due to no single index is adequate enough to provide a strong conclusive finding, the step to evaluate the model fit using a range of fit indices is deemed more appropriate. Table 5 tabulates the indices and benchmarks used to derive a conclusion on model fit. 


\section{Table 5}

Levels of acceptable fit of selected goodness of fit measures

\begin{tabular}{ll}
\hline Goodness of Fit Measures & Levels of Acceptable Fit \\
\hline Chi-square & $\mathrm{P} \geq 0.05$ \\
Chi-square/Degrees of Freedom & $\leq 3.00$ \\
Goodness-of-fit Index (GFI) & $\geq 0.90$ \\
Adjusted Goodness-of-fit Index (AGFI) & $\geq 0.90$ \\
Tucker Lewis Index (TLI) & $\geq 0.90$ \\
Comparative Fit Index (CFI) & \\
\hline
\end{tabular}

Adapted from Hair et al. (1998)

The measurement models of construct under study are visualized in Fig. 2 and Fig. 3. Fig. 2 shows that strategy implementation is suggested as a good fit with the measurement model. Non-significant values of chi square $(p=0.093)$ and chi square/degree of freedom $(\leq 3.00)$ indicate a good fit of measurement model. Fig. 2 also depicts that IFI (0.952), TLI (0.924), and CFI (0.949) measures surpassed the recommended levels.

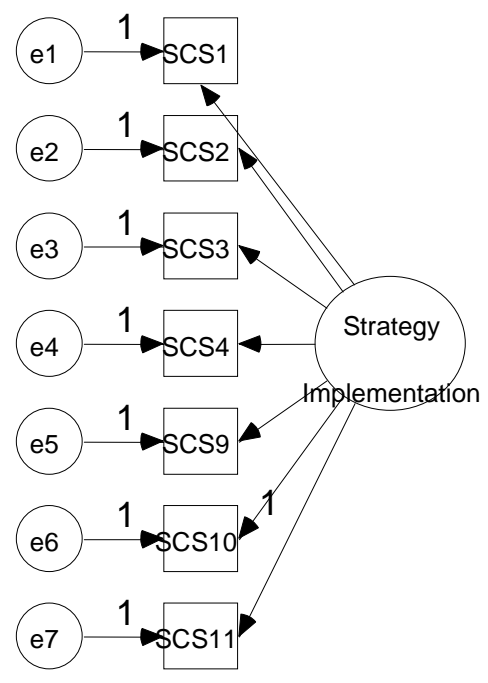

$$
\begin{aligned}
& \text { Chi-square }=21.634 \\
& \begin{aligned}
(p=0.093) \\
\text { Chi square } / \text { degree of freedom } \\
=21.634 / 14=1.54
\end{aligned}
\end{aligned}
$$

$\mathrm{IFI}=0.952 ; \mathrm{TLI}=0.924$ and $\mathrm{CFI}=0.949$

Fig. 2. Measurement model of strategic implementation

Fig. 3 shows that the chi square was significant $(\mathrm{p} \leq 0.05)$. However, the GFI $(0.854)$, IFI $(0.883)$, and CFI (0.875) were marginally below the recommended level. Given that, the measurement model of strategic resource allocation suggested a moderate fit of the measurement model.

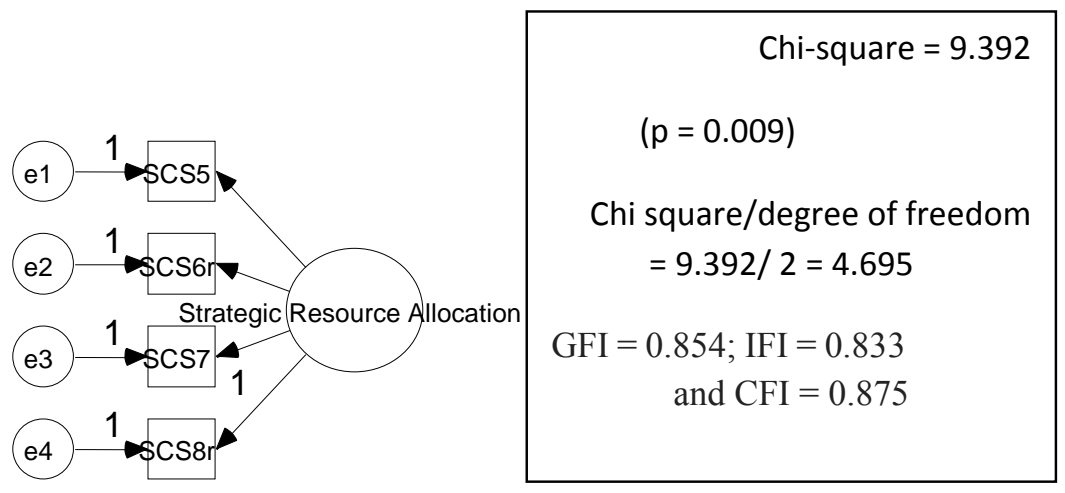

Fig. 3. Measurement model of strategic resource allocation 


\section{Implication}

This study has identified two main functions of SCS, namely strategy implementation and strategic resource allocation. The function of strategic implementation refers to the role of strategic control systems during the implementation stage, which covers the measuring, evaluating, feedback activities. The function of strategic resource allocation refers to the role of strategic control systems during the planning stage. This finding testifies the definition forwarded by Schendel and Hofer (1979). According to them, strategic control takes care of two things, namely plan of strategy and implementation of strategy, such as feedback and monitoring. A full version of their definition was reported in the earlier part of this paper. Based on the results of the reliability test, and exploratory and confirmatory factor analyses, this study offers the following definition of SCS: Strategic control systems focus on planning and implementation stages of a strategy. For the planning stage, strategic control systems play a role in developing the long-term plan, allocating resource, and translating strategy into measurable action. For the implementation stage, strategic control systems play a role in gaining consensus among organizational members, designing appropriate reward and penalty systems, and developing effective communication systems throughout the implementation process.

\section{Limitation}

This paper is not without limitation which needs to be considered when interpreting the findings of this study. Firstly, the data of this study were collected using questionnaire as an instrument. Therefore, all drawbacks related to a questionnaire-based survey should be acknowledged and addressed. Secondly, this study used the published literature as the main source for developing items into measures in the questionnaire. Although this approach may contribute to high content validity, it fails to appreciate the potential emerging issues related to the topic of interest. Therefore, future research may consider using primary sources, such as expert interview and Delphi method study to identify the important measures of SCS. Thirdly, this study investigated control systems under the environment of QM strategy. The requirements of QM towards control systems may be different from other management strategies. Therefore, future study may validate the findings of this present study by testing the instruments under different management strategies.

\section{Conclusion}

This paper has widened the border of knowledge of SCS literature, where the items for SCS construct were developed through a review of control systems literature and considered expert opinion. The instrument proposed in this study was systematically developed. Based on the reliability and validity analyses, the developed instrument was found to be reliable and valid, thus providing a valid and reliable research instrument for further use in investigations in this field of study. In summary, this study has revealed that SCS consists of two independent dimensions, namely strategy implementation and strategic resource allocation.

\section{References}

Akroyd, C. \& Maguire, W. (2011). The roles of management control in a product development setting. Qualitative Research in Accounting \& Management, 8(3), 212-237.

Ali, N. A., Mahat, F. \& Zairi, M. (2007). HRM issues in quality initiatives for Malaysian universities. International Journal of Economics and Management, 1(3), 437-452.

Bollen, K. A. (1989). Structural equations with latent variable. New York: Wiley.

Bromwich, M. (1990). The case for strategic management accounting: The role of accounting information for strategy in competitive markets. Accounting, Organizations and Society, 15, 2746.

Churchill, G. A. Jr. (1979). A paradigm for developing better measures of marketing constructs. Journal of Marketing Research, 16, 64-73. 
Goold, M. \& Quinn, J. J. (1990). The paradox of strategic controls. Strategic Management Journal, $11(1), 43-57$.

Goold, M. \& Quinn, J. J. (1993). Strategic control: Milestones for long-term performance. London: Pitman Publishing.

Govindarajan, V. \& Gupta, A. K. (1985). Linking control systems to business unit strategy: Impact on performance. Accounting, Organizations and Society, 10 (1), 51-66.

Haupt, T. C. (2004). Inhibiting factors of implementing total quality management on construction sites. The TQM Magazine, 16(3), 166-173.

Hoque, Z. (2003). Total Quality Management and the Balanced Scorecard approach: A critical analysis of their potential relationships and direction for research. Critical Perspectives on Accounting, 14 (5), 553-566.

Ittner, C. D. \& Larcker, D. F. (1997). Quality strategy, strategic control systems and organizational performance. Accounting, Organizations and Society, 22 (3/4), 295-314.

Kaplan, R. S. \& Norton, D. P. (1996). Using the balanced scorecard as a strategic management system. Harvard Business Review (Jan-Feb), 74 (1), 75-85.

Kaplan, R. S. \& Norton, D. P. (2000). The strategy-focused organization. USA: Harvard Business School Press.

Kerlinger, F. N. \& Lee, H. B. (2000). Foundations of behavioral research. $4^{\text {th }}$ ed. Harcourt College Publishers: Orlando, US.

Kumar, R., Garg, D. \& Garg, T.K. (2011). TQM success factors in North Indian Manufacturing and services industries, The TQM Journal, 23(1), 36-46.

Mooraj, S., Oyon, Y. \& Hostettler, D. (1999). The balanced scorecard: A necessary good or an unnecessary evil? European Management Journal, 17(5), 481-491.

Nunnaly, J. C. (1978). Psychometric theory. New York: McGraw Hill.

Powell, T. C. (1995). Total quality management as competitive advantage: A review and empirical study. Strategic Management Journal, 16 (1), 15-37.

Schendel, D. E. \& Hofer, C. W. (1979). Strategic management. Boston: Little, Brown.

Schreyogg, G. \& Steinmann, G. (1987). Strategic control: A new perspective. Academy of Management Review, 12, 91-103.

Sinclair, D \& Zairi, M. (2001). An empirical study of key elements of total quality-based performance measurement systems: A case study approach in the service industry sector. Total Quality Management, 12 (4), 535-550.

Simons, R. (1990). The role of management control systems in creating competitive advantage: New perspectives. Accounting, Organizations and Society, 15 (1/2), 127-143.

Takahiro, S. \& Jia, P. (2012). Comparison of internal control systems in Japan and China. International Journal of Business Administration, 3(1), 66-74

Yu, B.T.W., To, W.M. \& Lee, P.K.C. (2012). Quality management framework for public management decision making, Management Decision, 50(3), 420-438. 